\title{
Prácticas de interacción y de pensamiento democráticas y autoritarias. Una discusión clave para el trabajo y la democracia
}

Kliksberg, Naum*

\section{Resumen}

Este ensayo da respuesta a las consecuencias políticas que se desprenden del desarrollo de una política educativa autoritaria y la necesidad de generar un modelo educativo que permita la integración entre la escuela y la familia y la revalorización de los principios democráticos para poder reforzar un sistema político participativo y acorde con las nuevas exigencias.

Palabras clave: Democracia, políticas educativas, sistemas participativos.

* Sociólogo, psicólogo, psicólogo social. Ha prestado asesorla en pedagogía universitaria y políticas de desarrollo de las capacidades intelectuales a diversos países. Asesor de las Naciones Unidas. Ha asesorado en Venezuela entre otras universidades a LUZ, UCO, UCV, Universidad Simón Bolivar. Actualmente asesor del Congreso Argentino, y el Parlamento Latinoamericano en temas educativos. Autor de diversas obras y trabajos, entre ellas: La crisis pedagógica en las Universidades latinoamericanas (Universidad Central de Venezuela, Ediciones de la Biblioteca). Email: Naumk INEA.Com.Ar 


\title{
The Practice of Authoritarian and Democratic Interaction and Thought. A Key Discussion for Work and Democracy
}

\begin{abstract}
This essay responds to the political consequences which are generated by the development of an authoritative educational policy, and the need to generate an educational model which permits an integration of the school and the family, and the revaluation of democratic principles in order to build a participative political system in accord with new social demands and requirements.
\end{abstract}

Key words: Democracy, educational policy, participative systems.

\section{Modelos de pensamiento}

¿Cuál es la matriz social que forma ciudadanos democráticos o autoritarios?

¿Por qué hay una gran cantidad de personas que recibieron en la escuela durante años una muy buena "información" sobre la importancia de la vida democrática y luego como adultos interactúan en forma no democrática?

¿La escuela está formando individuos con estructuras de personalidad democráticas 0 autoritarias?

¿Cómo se puede mejorar en la escuela y en la familia la interacción democrática para formar ciudadanos con conductas más democráticas?

¿Hay relación entre la calidad del aprendizaje de las ciencias en la escuela y el tipo de interacciones democráticas $y / o$ autoritarias que los alumnos viven en el aula?

¿Cuáies son las consecuencias de políticas educativas autoritarias en el posterior comportamiento laboral y ciudadano sobre este tema?
A continuación se exponen algunos elementos para aportar a la reflexión sobre estos temas.

El niño se relaciona en la escuela primaria (con sus maestros y con los otros alumnos) y en su familia (con sus hermanos y padres) a través de tres formas de interacción básicas:

1. De aceptación pasiva.

2. De imposición autoritaria.

3. De diálogo democrático.

Cada una de estas modalidades de interacción humana forma en el niño una determinada "forma de pensar" e influye en la conformación de sus características de personalidad:

1. La interacción de aceptación pasiva, estructura una forma de pensar sometida, en la cual se acepta sin elaborar lógica y críticamente, sin inquirir sobre los fundamentos de la información, orden o propuesta del otro.

2. La interacción de imposición autoritaria, lleva una forma de pensar en la cual prevalece no sólo el objetivo de 
imponerse al otro, sino de hacerlo sólo en base a evaluar las fuerzas coercitivas que cada uno tiene para lograrlo (sea para rechazar o para atacar al otro).

3. La interacción dialogal democrática, desarrolla una forma de pensar crítica, de mejor calidad en su lógica; se valoran los argumentos, se escucha, hay un esfuerzo por entender al otro y en hacerse entender por él (esfuerzo que también desarrolla una mejor calidad del área afectiva).

Este tipo de interacción es la más eficiente para dialogar sobre los conceptos cientfficos, cotejarlos, evaluarlos, admitir con naturalidad las discrepancias, lo diferente, y para "aprender a pensar" científicamente. Eleva de manera significativa la calldad del aprendizaje de los contenidos curriculares en cada asignatura.

\section{Hacia estructuras de personalidad más democráticas}

El pregonar las bondades de la vida democrática es útil pero no es suficiente para producir la conducta democrática. Para ello es necesario aprender la interacción democrática practicándola, ejerciéndola cotidianamente, sobre todo en el aula escolar y en el ámbito familiar. De este modo se pueden formar ciudadanos con estructuras de personalidad más democráticas. También es la interacción óptima para desarrollar mejor en los alumnos su inteligencia, creatividad, personalidad y los valores solidarios. La familia y el aula escolar son las principales matri- ces formadoras de las conductas democráticas o autoritarias del adulto.

Un niño aprende al mismo tiempo a interactuar y a pensar pasiva y autoritariamente, cuando participa o presencia interacciones en las cuales uno se "impone" a otro que toma un rol de "aceptación pasiva". Son dos tipos de conducta que se producen y se aprenden simultáneamente, son dos caras de una misma unidad de interacción.

Si este aprendizaje predomina durante años en el aula (en la relación con sus maestros y con los otros alumnos) y en su familia, se constituirá en el niño una estructura de personalidad con características pasivas y autoritarias al mismo tiempo.

Ello explica por qué estas personas toman un rol de aceptación pasiva, sometida, cuando se relacionan con otra que es más fuerte (por la autoridad que tenga); pero cuando ellos son los que tienen más poder ejercen el rol autoritario (en su familia, en el trabajo, etc.).

Cuando en una escuela predomina en el aula la interacción de imposición autoritaria por un lado y de aceptación pasiva por el otro (sometida), no se forma adecuadamente en los niños una estructura de personalidad democrática, aunque se les enseñen todos los conocimientos "teóricos" sobre la importancia de la democracia, lo cual es muy importante hacerlo, pero no es suficiente. En la conducta del niño y luego del adulto prevalecerá el aprendizaje que internalizó desde pequeño en el tipo de "interacciones" que vivenció.

Esto permite comprender mejor las causas de las crecientes agresiones que los niños y jóvenes están produciendo, a 
sus propios familiares y a otros. Cada vez a edad más temprana los niños y adolescentes sienten que empiezan a tener un poco de poder y lo comienzan a "practicar", "ejercer", aplicando el aprendizaje que realizaron del rol autoritario, rol que ya vimos se aprende en la familia, en el aula escolar y en una medida menor aunque importante, en la televisión.

Hay mucho que se puede mejorar en la tarea educativa de la escuela y de la familia, para formar ciudadanos que no solo "sepan" sobre democracia, sino que sobre todo tengan "estructuras de personalidad más democráticas", lo cual producirá "conductas" democráticas.

Para que sea más exitosa la escuela en lograr este objetivo, es muy importante que los padres participen activamente en la dinámica de la escuela, prestando especial atención a motivar el empleo en el aula de las prácticas pedagógicas que posibilitan las interacciones democráticas y neutralicen las autoritarias. Por ejemplo: el solo hecho de que un solo padre participe como observador silencioso en la última silla del aula mejora considerablemente las interacciones democráticas entre maestro-alumnos y entre los alumnos. Con ello también aumenta la calidad de la enseñanza (es la forma más económica, ya que no requiere ningún costo y puede impactar inmediatamente la calidad del aprendizaje).

\section{Prácticas autoritarias en la escuela}

Cuando en un pais hay un sistema político democrático ello no significa que en las instituciones predomine una dinámica democrática.
En la escuela suele darse una diaria confrontación entre prácticas pedagógicas democráticas y autoritarias.

Algunas de las autoritarias son:

- El que se le exija al alumno memorizar en lugar de reflexionar, que no se privilegie el brindar a los alumnos talleres destinados a mejorar su capacidad de reflexión (tipo "aprendiendo a pensar", "desarrollo de la inteligencia", etc.).

- No fomentar la curiosidad en los alumnos, inhibir las preguntas en el aula, no considerar importante la opinión de los alumnos sobre lo que sucede en el aula y sobre otros aspectos del proceso educativo.

- No permitir que se organicen y participen como ejercicio democrático en ningún nivel de la toma de decisiones (disciplinarias, diseño de actividades escolares, etc.).

- No presentar la diversidad de teorias existentes en los conceptos que se enseñan, o presentarlos como "la verdad" única e indiscutible.

- Basar el aprendizaje sólo en lo que "dice" el docente, no presentar otras fuentes divergentes.

- No trabajar en el proceso de aprendizaje incluyendo los aspectos afectivos de los alumnos. No valorar el potencial educativo de reflexionar con los alumnos sobre las características de las interacciones cognitivas y afectivas que tienen en el aula entre ellos $y$ con el docente.

- Sentar a los alumnos en fila, imponiendo así geográficamente una interacción comunicacional unidireccional y no en semicirculo para facilitarla interacción democrática multidireccional. 
- Justificar el no esforzarse más en mejorar la eficacia de la institución educativa, sobre todo en cuanto a ser fuente nutriente de valores, con la argumentación de que es imposible neutralizar, ni siquiera en parte, las influencias negativas que los alumnos pueden recibir de la televisión y de su familia.

- No incluir en el aula lo que pasa fuera de ella. Aunque los chicos vengan profundamente sensibilizados por una noticia que ese día se presentó en todos los medios de difusión y que conmovió a todo el país, la rigidez propia de la pedagogía autoritaria no aprovecha la inmensa utilidad pedagógica que significa en tales circunstancias reflexionar acerca de esa noticia. Se desperdicia así muchas veces la posibilidad de producir en esos momentos los aprendizajes más importantes que puede tener el alumno, sobre todo en la formación de sus valores.

- No permitir una participación más democrática y horizontal entre docentes y directivos.

- Aunque se emplee un discurso que hable positivamente de la necesidad de que los padres se integren más activamente a la escuela, en la realidad no se hace nada para fomentarlo. Sólo se estimula que organicen actividades deportivas y/o que provean de dinero a la escuela. Si los padres tratan de que se mejoren aspectos más importantes relativos a lo que se enseña y como se enseña entonces se trata de inhibirlos.

- No considerar importantes sus opiniones sobre los problemas de la escuela, por lo tanto no realizar encues- tas de opinión entre ellos. Es frecuente que los padres manifiesten que en siete años que sus hijos estuvieron en la escuela primaria nunca la directora ni los docentes que tuvieron sus hijos le preguntaron qué aspectos de la dinámica escolar estiman que hay que mejorar. Esta conducta con frecuencia llega al extremo de ni siquiera poner a disposición de los padres (y de los alumnos) un buzón para que puedan exponer sugerencias que estimen de utilidad.

- No aceptar que las clases puedan ser presenciadas por uno de los padres con pretexto que no tiene ningún fundamento pedagógico serio.

- No presentar a los padres una información transparente sobre la administración económica de la escuela a la cual van sus hijos.

Estas limitaciones autoritarias enganchan en muchos padres los contenidos pasivos que desarrollaron en sus estructuras de personalidad, por to cual aceptan esta situación sometiéndose a ella. Unos lo toman como un mal naturale inevitable, otros desarrollan un mecanismo psicológico de negación y racionalización.

Muchos son los docentes que hacen lo posible para que no se implementen estas acciones autoritarias, otros docentes las fomentan porque es grande el poder que sienten al estar en un aula frente a niños, lo cual les aumenta y permite canalizar sus aspectos más autoritarios.

\section{Algunas conclusiones}

El nivel de eficiencia que obtenga una escuela en el logro del objetivo de ca- 
pacitar adecuadamente a sus alumnos, depende de la calidad de la participación que los padres tengan en ella, sobre todo en el aspecto de motivar al uso de prácticas pedagógicas que posibiliten las interacciones democráticas en el aula.

El modelo pedagógico autoritario pudo desarrollarse por mucho tiempo porque el tipo de alumnos que producía podia insertarse laboralmente en el sistema económico. ¡Esto ya no es asíl

En la actualidad, la escuela que emplea una pedagogía autoritaria forma ciudadanos que serán autoritarios jcon más posibilidades por ello de ser desocupados!

Esto no le sirve a los alumnos, a sus familias, a las empresas, ni al país.

Un pais que quiere desarrollarse necesita escuelas que permitan lograr una capacitación de excelencia. Para lograria ya no puede continuar tolerando en las prácticas pedagógicas las manifestaciones autoritarias.

Empieza a entrar en crisis la pedagogía autoritaria porque presenciamos en todo el mundo un cambio radical en el tipo de características que solicita el mercado laboral de los trabajadores y de los profesionales. En el momento actual las empresas y los padres coinciden en exigir a las instituciones educativas que desde los 3 años hasta los estudios de posgrado formen personas aptas para poder insertarse laboralmente. Para ello las instituciones educativas no solo deben transmitir conocimientos. También deben desarrollar en el alumno características de personalidad que lo capaciten para adaptarse rápidamente a los cambios vertiginosos en el medio laboral, realizar autoaprendizajes en forma continua, poder trabajar en interacción grupal, no sólo disponer de información sino también saber como manejarla, relacionarla, solucionar problemas, ser flexibles, "generar pensamientos creativos", tener "coraje creativo" (sin el cual no podrán implementar los pensamientos creativos, los cuales serán autocensurados), tener iniciativa propia, y otras características que no pueden originarse satisfactoriamente en un modelo pedagógico autoritario y sí en el democrático.

Podemos concluir de esta forma:

Cuantas más interacciones democráticas se viven desde la niñez en la familia y en la escuela se produce una persona mejor capacitada para el trabajo. Que valora más la vida democrática en su país, defiende y enriquece más la dinámica democrática en cada institución en la cual se desempeña, sea política, laboral, familiar e interactuará con el prójimo con una mejor calidad humana. 